\title{
Advances in clinkering technology of calcium sulfoaluminate cement
}

\section{Isabel Galan}

Department of Chemistry, University of Aberdeen, Aberdeen, UK Institute for Applied Geosciences, Graz University of Technology, Graz, Austria (corresponding author: igalangarcia@tugraz.at) (Orcid:0000-0001-6845-471X)

\section{Ammar Elhoweris}

Department of Chemistry, University of Aberdeen, Aberdeen, UK; Gulf Organisation for Research and Development, Qatar Science and Technology Park, Doha, Qatar

\section{Theodore Hanein}

School of Engineering, University of Aberdeen, Aberdeen, UK; Department of Materials Science and Engineering, University of Sheffield, Sheffield, UK

Marcus N. Bannerman

School of Engineering, University of Aberdeen, Aberdeen, UK

Fredrik P. Glasser

Department of Chemistry, University of Aberdeen, Aberdeen, UK

A new method for producing calcium sulfoaluminate (C̄̄A) clinkers is described. Sulfur is introduced from the gas phase as sulfur dioxide and oxygen and reacts with solids during clinkerisation. In this paper, the laboratory experiments are described and thermodynamic calculations are presented. The sulfur-containing phases ye'elimite and ternesite were stabilised together with belite to produce clinkers with various mineralogies. The influences of temperature and sulfur dioxide partial pressure were analysed and their effect on the formation of undesirable anhydrite and gehlenite was examined. The process by which a potentially hazardous waste material such as sulfur can be used as raw material, and possibly as fuel, to form C̄́A cements, is shown to be successful.

\section{Introduction}

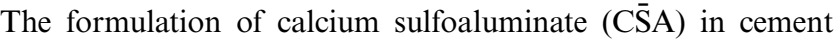
chemistry notation, where $\mathrm{C}$ represents calcium oxide $(\mathrm{CaO})$, $\overline{\mathrm{S}}$ represents sulfur trioxide $\left(\mathrm{SO}_{3}\right)$ and $\mathrm{A}$ means aluminium oxide $\left(\mathrm{Al}_{2} \mathrm{O}_{3}\right)$ cements is undergoing rapid development as a prelude to widespread application. The advantages of $\mathrm{C} \overline{\mathrm{S}} \mathrm{A}$ cements relative to ordinary Portland cement have been reported elsewhere (Gartner, 2004; Gartner and Hirao, 2015; Gartner and MacPhee, 2011; Hanein et al., 2016b; Juenger et al., 2011) and include reduction of carbon dioxide emissions and lower specific energy requirements.

The major benefits of $\mathrm{CS} A$ cements primarily arise due to the presence of abundant ye'elimite $\left(\mathrm{C}_{4} \mathrm{~A}_{3} \overline{\mathrm{S}}\right)$ giving, among other advantages, high early strength, but other sulfur-containing phases, including ternesite $\left(\mathrm{C}_{5} \mathrm{~S}_{2} \overline{\mathrm{S}}\right)$ and anhydrite $(\mathrm{C} \overline{\mathrm{S}})$ can occur. $\bar{C} \bar{S} A$ clinkers require a source of sulfur trioxide, commonly provided by the addition of anhydrite to the clinker or either active anhydrite or gypsum to the raw mix. However, the formation of $\mathrm{C} \overline{\mathrm{S}} \mathrm{A}$ clinker is challenging, particularly under laboratory conditions, due to volatilisation of sulfur trioxide (the stable gas phase lost at elevated temperatures is in fact a mixture of sulfur dioxide $\left(\mathrm{SO}_{2}\right)$ and oxygen from the solids) or, more generally, the inability to stabilise the clinker sulfur trioxide content.

At clinkering temperatures, typically $>1250^{\circ} \mathrm{C}$ but lower than melting temperatures, which occur at $>1300^{\circ} \mathrm{C}$ (Idrissi et al., 2010; Touzo et al., 2013), the loss of sulfur trioxide limits clinkering to a rather narrow window of temperatures and requires that the exhaust gas from the kiln is monitored and, if necessary, scrubbed to remove sulfur oxides $\left(\mathrm{SO}_{x}\right)$. This paper shows that this loss need not be a problem, particularly on an industrial scale: the high pressures of sulfur oxides can be used to an advantage and vapour transport is shown to be an effective way of achieving reactions among the components of the raw meal. Kinetic studies show that the equilibrium between gas and solid components is achieved rapidly at $\approx 1300^{\circ} \mathrm{C}$, even in the rapid flow rates achieved in commercial kilns.

Most experience of clinkering has been gained in laboratory experiments supplemented by pilot-plant 'burns'. A somewhat different approach was taken in the work reported in this paper: experiments and thermodynamic calculations were combined to elucidate the clinkering process. This work demonstrated the importance of the vapour phase in clinkering and led to changes in kiln operation: the kiln was modified to work as a semi-sealed system in order to gain control of the kiln atmosphere. This was paralleled by using a small-capacity (10-100 g) laboratory kiln, permitting independent control of temperature and gas partial pressures of sulfur dioxide and oxygen and a total pressure of 1 bar (100 kPa).

Numerous high-temperature thermodynamic equilibrium models based on Gibbs energy minimisation have been developed for cement clinker predictions and these have proved useful in cement research (Barry and Glasser, 2000; Hökfors et al., 2014, 2015). Thermodynamic databases used to calculate high-temperature cement phase equilibria include MTdata (Davies et al., 2002), FactSage (Bale et al., 2002), HSC (Roine, 2002) and that recently developed by Hanein et al. (2015b). As shown by Hanein et al. (2015a), the stability of ye'elimite at clinkering temperatures is dependent on the fugacities (equated here with partial pressures) of both sulfur dioxide and oxygen in the kiln atmosphere, and a thermodynamic model considering both the clinker phases and the atmosphere was developed to model the reaction path and optimise operating conditions for the production of $\overline{C S} A$ clinkers. 
Advances in Cement Research

Volume 29 Issue 10
Advances in clinkering technology of

calcium sulfoaluminate cement

Galan, Elhoweris, Hanein, Bannerman and Glasser

\section{Experimental programme}

\section{Furnace}

Experiments were conducted in a tube furnace specifically modified to operate at $1 \mathrm{bar}(100 \mathrm{kPa})$ total pressure but with controlled partial pressures of sulfur dioxide and oxygen (Galan et al., 2014); the furnace is shown in Figure 1. Premixed gases, whose rates were monitored by means of precision mass flow controllers (Bronkhorst, NL), passed through the non-rotating furnace tube, maintaining the desired atmosphere during the experiment. The discharge end of the tube was connected to a scrubber that absorbs and neutralises unreacted sulfur oxides prior to gas discharge to the atmosphere. In this way, the exit gases comprised less than $1 \mathrm{ppm}$ sulfur oxides. Temperature patterns (heating, idling and cooling) were programmed by means of the furnace control box.

\section{Raw materials}

The following two sets of raw materials were used in the experiments.

Set 1: laboratory grades of aluminium oxide $\left(\mathrm{Al}_{2} \mathrm{O}_{3}\right)$ (Sigma-Aldrich $265497,10 \mu \mathrm{m}, 99 \cdot 7 \%$ ), silicon dioxide $\left(\mathrm{SiO}_{2}\right.$ or quartz) (Fluka $83340,>230$ mesh, >95\%), calcium carbonate $\left(\mathrm{CaCO}_{3}\right)$ (Sigma-Aldrich 795445 , $>99 \%$ ), iron oxide $\left(\mathrm{Fe}_{2} \mathrm{O}_{3}\right)$ (Fisher Scientific $\mathrm{I} / 1150 / 53$, general purpose grade) and calcium sulfate $\left(\mathrm{CaSO}_{4}\right)$ (Fisher C/2440/60, >95\%).
- Set 2: commercially available bauxite, clay and limestone. The oxide composition of the commercially available raw materials is shown in Table 1. The bauxite and clay were provided by Zhengzhou Haixu Abrasives Co. Ltd (China) and the limestone was provided by Samin (France).

In both cases the raw materials were weighed, mixed, placed in crucibles or boats of aluminous porcelain or platinum, and introduced into the furnace, which was ramped up to an isothermal level.

\section{Experiments}

The variables evaluated in the experiments included sulfur dioxide partial pressure, peak clinkering temperature, proportioning of the raw materials and time. The oxygen partial pressure was kept sufficiently high to ensure oxidising conditions to $(a)$ prevent the formation of undesirable sulfides and (b) ensure all sulfur dioxide was able to oxidise to sulfur trioxide if the equilibrium sought demanded the formation of solids containing sulfate. The minimum oxygen excess was targeted at $100 \%$, resulting in weight ratios of sulfur dioxide:oxygen of at least 1:0·5 (or sulfur dioxide:air ratio of $1: 2 \cdot 5$ ).

Approximately 25 compositions were tested and in all cases the atmospheric conditions were such that sulfur trioxide was transferred from vapour to solid to achieve the target

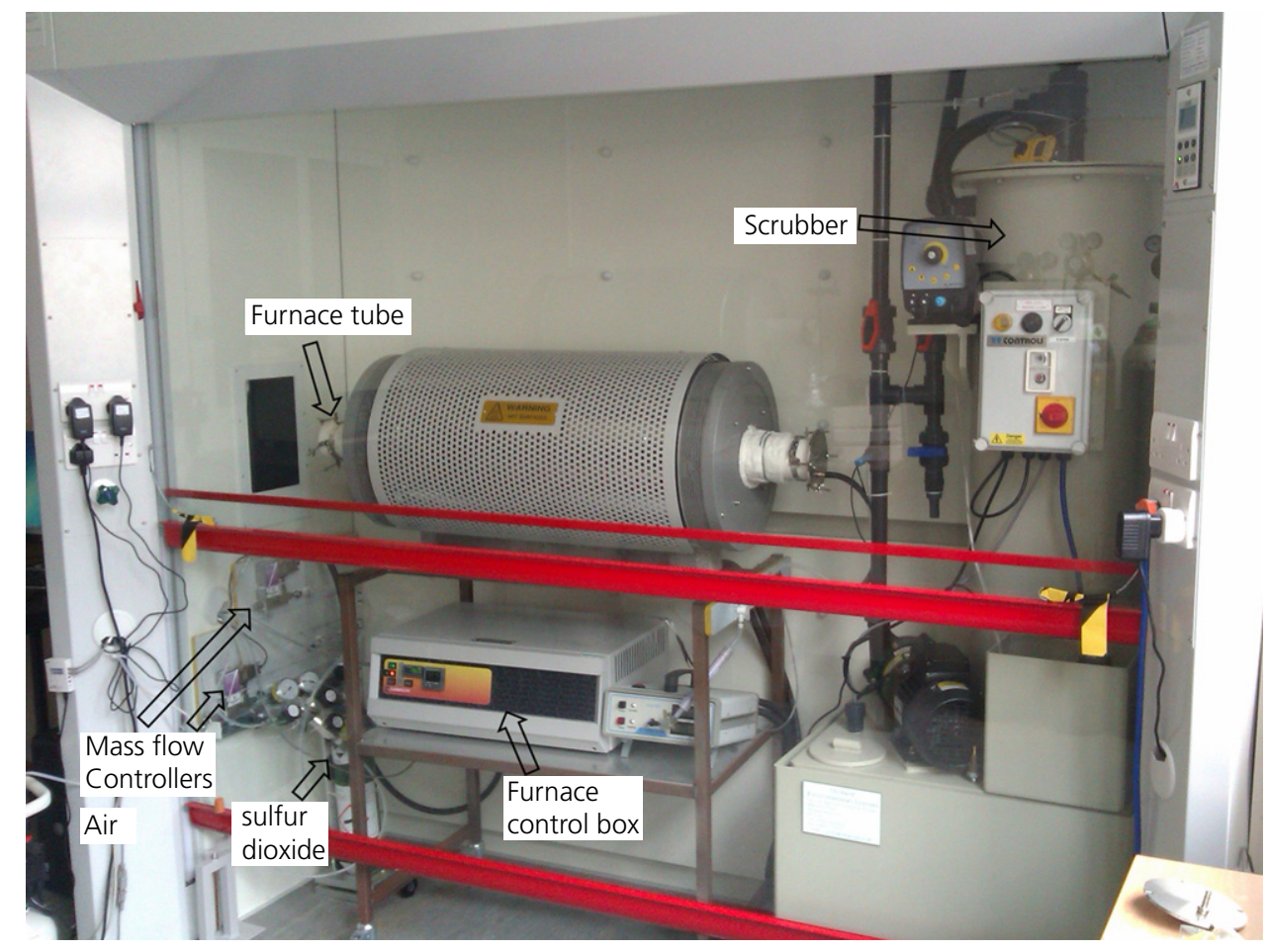

Figure 1. Furnace used for the experiments where sulfur was transferred from the gas to the solid phase. The entire unit was housed in a ventilated enclosure, $2400 \mathrm{~mm}$ width $\times 640 \mathrm{~mm}$ depth 
mineralogy. This was achieved by providing an automatic check that the kinetics of transfer of sulfur species from gas to solid were rapid. The experiments evaluated

Table 1. Oxide composition of raw materials used for the experiments (X-ray fluorescence measurements of bauxite and clay were performed at the School of Geosciences, Edinburgh University; oxide composition of limestone was provided by the supplier (Samin))

\begin{tabular}{lccc} 
& Bauxite & Clay & Limestone \\
\hline Silicon dioxide $\left(\mathrm{SiO}_{2}\right): \%$ & 11.52 & 39.24 & 0.1 \\
Aluminium oxide $\left(\mathrm{Al}_{2} \mathrm{O}_{3}\right): \%$ & 69.32 & 38.18 & 0.00 \\
Iron oxide $\left(\mathrm{Fe}_{2} \mathrm{O}_{3}\right): \%$ & 1.21 & 5.98 & 0.009 \\
Magnesium oxide $(\mathrm{MgO}): \%$ & 0.00 & 0.06 & 0.26 \\
Calcium oxide $(\mathrm{CaO}): \%$ & 0.16 & 0.87 & 55.70 \\
Sodium oxide $\left(\mathrm{Na}_{2} \mathrm{O}\right): \%$ & 0.00 & 0.00 & 0.00 \\
Potassium oxide $\left(\mathrm{K}_{2} \mathrm{O}\right): \%$ & 0.455 & 0.624 & 0.00 \\
Titanium dioxide $\left(\mathrm{TiO}_{2}\right): \%$ & 3.409 & 1.773 & 0.00 \\
Manganese oxide $(\mathrm{MnO}): \%$ & 0.000 & 0.001 & 0.00 \\
Phosphorus pentoxide $\left(\mathrm{P}_{2} \mathrm{O}_{5}\right): \%$ & 0.081 & 0.088 & 0.00 \\
Loss on ignition: \% & 13.44 & 13.08 & 44.00 \\
& & &
\end{tabular}

ne thormation of anhydrite $(\mathrm{C} \overline{\mathrm{S}})$ by the transfer of sulfur dioxide plus oxygen from vapour to powdered calcium carbonate or calcium oxide

the formation of ye'elimite $\left(\mathrm{C}_{4} \mathrm{~A}_{3} \overline{\mathrm{S}}\right)$ and ternesite $\left(\mathrm{C}_{5} \mathrm{~S}_{2} \overline{\mathrm{S}}\right)$ by the transfer of sulfur dioxide plus oxygen to appropriate mixes of calcium oxide and aluminium oxide, and calcium oxide and silicon dioxide, respectively

- clinkers designed to contain $\mathrm{C}_{4} \mathrm{~A}_{3} \overline{\mathrm{S}}$, belite $\left(\mathrm{C}_{2} \mathrm{~S}\right)$ and ferrite (solid solution $\mathrm{C}_{2} \mathrm{~F}-\mathrm{C}_{6} \mathrm{~A}_{2} \mathrm{~F}$ ) by the transfer of sulfur dioxide plus oxygen to mixes of calcium oxide, aluminium oxide, silicon dioxide and iron oxide.

The different compositions were prepared by hand mixing (for $5 \mathrm{~min}$ ) the calculated amounts of dry solid reactants using a mortar and pestle with a few drops of ethanol added to aid homogenisation. The resulting mix was dried in an oven at $\approx 100^{\circ} \mathrm{C}$ for $2 \mathrm{~h}$ to remove the alcohol. Clinkers were prepared from laboratory-grade materials in the form of pellets (Table 2) and powder (Table 3) and from commercially available raw materials (Table 4) in powder form with a particle size of

Table 2. Experimental conditions used for clinkers made with mixes of calcium carbonate, silicon dioxide, aluminium oxide and iron oxide in pellet form

\begin{tabular}{|c|c|c|c|}
\hline Target mineralogy & Input & Mass flow rate sulfur dioxide:air: $\mathrm{g} / \mathrm{min}$ & Temperature, $T:{ }^{\circ} \mathrm{C}$ \\
\hline \multicolumn{4}{|l|}{ Target composition 1} \\
\hline $60 w t \% C_{4} A_{3} \bar{S}$ & 48.1 wt $\%$ calcium oxide & $0.04: 0 \cdot 1(1: 2 \cdot 5)$ & 1300 \\
\hline $20 w t \% C_{2} S$ & 7.6 wt\% silicon dioxide & & \\
\hline $20 w t \% \mathrm{C}_{6} \mathrm{~A}_{2} \mathrm{~F}$ & 37.2 wt $\%$ aluminium oxide & & \\
\hline & $7 \cdot 1$ wt $\%$ iron oxide & & \\
\hline \multicolumn{4}{|l|}{ Target composition 2} \\
\hline $40 w t \% C_{4} A_{3} \bar{S}$ & $52.7 w t \%$ calcium oxide & $0 \cdot 04: 0 \cdot 1(1: 2 \cdot 5)$ & 1300 \\
\hline $40 w t \% C_{2} S$ & 14.7 wt $\%$ silicon dioxide & & \\
\hline $20 w t \% \mathrm{C}_{6} \mathrm{~A}_{2} \mathrm{~F}$ & 25.6 wt $\%$ aluminium oxide & & \\
\hline & 6.9 wt $\%$ iron oxide & & \\
\hline \multicolumn{4}{|l|}{ Target composition 3} \\
\hline $20 w t \% C_{4} A_{3} \bar{S}$ & $57 \cdot 1 \mathrm{wt} \%$ calcium oxide & $0 \cdot 04: 0 \cdot 1(1: 2 \cdot 5)$ & 1300 \\
\hline $60 w t \% C_{2} S$ & $21.5 w t \%$ silicon dioxide & & \\
\hline $20 w t \% \mathrm{C}_{6} \mathrm{~A}_{2} \mathrm{~F}$ & 14.6 wt $\%$ aluminium oxide & & \\
\hline & $6.8 w t \%$ iron oxide & & \\
\hline
\end{tabular}

Table 3. Experimental conditions used for clinkers made with mixes of calcium carbonate, silicon dioxide, aluminium oxide, iron oxide and calcium sulfate in powder form. The 'Target mineralogy' and 'Input' data apply to multiple experiments

\begin{tabular}{|c|c|c|c|c|}
\hline Experiment & Target mineralogy & Input & Mass flow rate sulfur dioxide:air: $\mathrm{g} / \mathrm{min}$ & $T:{ }^{\circ} \mathrm{C}$ \\
\hline 1 & \multirow{9}{*}{$\begin{array}{l}30 w t \% C_{4} A_{3} \bar{S} \\
60 w t \% C_{2} S \\
10 w t \% C_{6} A_{2} F\end{array}$} & \multirow{9}{*}{$\begin{array}{l}52 \cdot 1 \text { wt\% calcium oxide } \\
20 \cdot 9 \text { wt } \% \text { silicon dioxide } \\
6 \cdot 7 \text { wt } \% \text { calcium sulfate } \\
18.0 \text { wt } \% \text { aluminium oxide } \\
2 \cdot 3 \text { wt } \% \text { iron oxide }\end{array}$} & $1 \cdot 05: 2 \cdot 63(1: 2 \cdot 5)$ & 1280 \\
\hline 2 & & & $0 \cdot 105: 2 \cdot 63(1: 25)$ & 1280 \\
\hline 3 & & & $0 \cdot 1: 5(1: 50)$ & 1280 \\
\hline 4 & & & $0.04: 4(1: 100)$ & 1280 \\
\hline 5 & & & $0.04: 2(1: 50)$ & 1230 \\
\hline 6 & & & $0.04: 1(1: 25)$ & 1230 \\
\hline 7 & & & $0 \cdot 088: 2 \cdot 204(1: 25)$ & 1200 \\
\hline 8 & & & $0.055: 2 \cdot 204(1: 25)$ & 1250 \\
\hline 9 & & & $0 \cdot 055: 2 \cdot 204(1: 25)$ & 1270 \\
\hline 10 & $60 \mathrm{wt} \% \mathrm{C}_{4} \mathrm{~A}_{3} \overline{\mathrm{S}}$ & $40 \cdot 9$ wt\% calcium oxide & $0 \cdot 088: 2 \cdot 204(1: 25)$ & 1200 \\
\hline \multirow[t]{4}{*}{11} & $30 w t \% C_{2} S$ & $10 \cdot 5$ wt $\%$ silicon dioxide & \multirow[t]{4}{*}{$0 \cdot 088: 2 \cdot 204(1: 25)$} & \multirow[t]{4}{*}{1250} \\
\hline & $10 w t \% \mathrm{C}_{6} \mathrm{~A}_{2} \mathrm{~F}$ & 13.4 wt $\%$ calcium sulfate & & \\
\hline & & 33.0 wt $\%$ aluminium oxide & & \\
\hline & & $2 \cdot 3$ wt $\%$ iron oxide & & \\
\hline
\end{tabular}


Table 4. Experimental conditions used for clinkers made with commercial-grade raw materials. The 'Target mineralogy' and 'Input' data apply to multiple experiments

\begin{tabular}{|c|c|c|c|c|c|}
\hline Experiment & Target mineralogy & Input & $\begin{array}{l}\text { Flow rates sulfur } \\
\text { dioxide:air: } \mathrm{g} / \mathrm{min}\end{array}$ & Temperature: ${ }^{\circ} \mathrm{C}$ & $\begin{array}{l}\text { Time at peak } \\
\text { temperature: } \min \end{array}$ \\
\hline 1 & $36 w t \% C_{4} A_{3} \bar{S}$ & 12.2 wt $\%$ bauxite & $0.04: 1(1: 25)$ & 1250 & 120 \\
\hline 2 & 32 wt $\% \mathrm{C}_{2} \mathrm{~S}$ & 68.4 wt $\%$ limestone & $0.04: 1(1: 25)$ & 1300 & 120 \\
\hline 3 & $9 \mathrm{wt} \% \mathrm{C}_{4} \mathrm{AF}$ & 19.5 wt \% clay & $0.04: 4(1: 100)$ & 1250 & 120 \\
\hline 4 & 23 wt $\%$ C S & & $0 \cdot 04: 4(1: 100)$ & 1300 & 120 \\
\hline 5 & $34 w t \% C_{4} A_{3} \bar{S}$ & $6.6 w t \%$ bauxite & $0.04: 4(1: 100)$ & 1300 & 120 \\
\hline 6 & 42 wt $\% C_{2} S$ & 67.3 wt $\%$ limestone & $0.04: 4(1: 100)$ & 1300 & 60 \\
\hline 7 & 11 wt $\% \mathrm{C}_{4} \mathrm{AF}$ & $26 \cdot 1$ wt $\%$ clay & $0.04: 4(1: 100)$ & 1300 & 30 \\
\hline 8 & 13 wt $\%$ CS & & $0.04: 4(1: 50)$ & 1275 & 120 \\
\hline 9 & & & $0.04: 2(1: 100)$ & 1275 & 120 \\
\hline
\end{tabular}

approximately $40 \mu \mathrm{m}$. In experiments $1-11$ in Table 3 , laboratory-grade calcium sulfate was also added to the raw mix.

\section{Clinkers made with laboratory-grade materials in pellet form without calcium sulfate}

Three different mixes were used to prepare $13 \mathrm{~mm}$ diameter pressed pellets. These were fired at $1300^{\circ} \mathrm{C}$ for $30 \mathrm{~min}$. The targeted mineralogies and gas flow conditions are shown in Table 2. The amount of sulfur introduced into the furnace was in all cases sufficient to form the target amount of $\mathrm{C}_{4} \mathrm{~A}_{3} \overline{\mathrm{S}}$. The rate of sulfur dioxide used allowed for the formation of a minimum of $1.5 \mathrm{~g}$ of 'sulfur trioxide' in the $30 \mathrm{~min}$ that the gases were passing through the tube furnace. The quantities of sulfur trioxide required to obtain target compositions 1,2 and 3 in Table 2 were $0 \cdot 21,0 \cdot 13$ and $0.05 \mathrm{~g}$, respectively. $\mathrm{C}_{6} \mathrm{~A}_{2} \mathrm{~F}$ was chosen as the target stoichiometry for ferrite based on trends shown by Touzo et al. (2013) for feeds with high aluminium oxide:iron oxide ratios, but changes were made in the course of the work because experiments showed that the actual ferrite lay close to $\mathrm{C}_{4} \mathrm{AF}$.

\section{Clinkers made with laboratory-grade materials in powder form including calcium sulfate}

In this set of experiments the sulfur dioxide plus oxygen flow was turned on when the furnace reached $\approx 600^{\circ} \mathrm{C}$ during ramp up (at $20^{\circ} \mathrm{C} / \mathrm{min}$ ) and turned off during the cooling cycle (at $20^{\circ} \mathrm{C} / \mathrm{min}$ ) below $\approx 600^{\circ} \mathrm{C}$. To facilitate reactions between the gas and solid phases, a layer of the solid reactants several millimetres in thickness, $\approx 10 \mathrm{~g}$ in total, was placed in a $15 \mathrm{~cm}$ long ceramic boat in the middle of the hot zone of the tube (at constant temperature). The mix proportions used and the experimental conditions (sulfur dioxide:air ratios and temperature) are summarised in Table 3. The time allowed for reaction, $\approx 120 \mathrm{~min}$, did not include ramping up and down times. The amount of calcium sulfate was, in all cases, sufficient to form the desired target compositions; the sulfur dioxide plus oxygen atmosphere was used to preclude sulfur losses from the solids and to keep an atmosphere with an excess of 'sulfur trioxide' at all times.
Clinkers made with commercially available raw materials Two different mixes were used under two different conditions. The mixes used were calculated for a certain target composition assuming that the silica (from both the clay and bauxite) would form belite $\left(\mathrm{C}_{2} \mathrm{~S}\right)$, the iron oxide would combine with calcium and aluminium oxides to form ferrite $\left(\mathrm{C}_{4} \mathrm{AF}\right)$ and excess aluminium oxide would react to form ye'elimite $\left(\mathrm{C}_{4} \mathrm{~A}_{3} \overline{\mathrm{S}}\right)$. The gas atmosphere was on from the beginning to the end of the experiments (to prevent possible sulfur losses during ramping up and down). As in the laboratory-grade experiments, a layer of the solid reactants several millimetres thick, $\approx 10 \mathrm{~g}$ in total, was placed in a ceramic boat in the middle of the hot zone of the tube (at constant temperature). The proportions used and the experimental conditions (sulfur dioxide partial pressure, temperature and time) are summarised in Table 4. The excess sulfur trioxide in these experiments was higher than the theoretical amounts: the mass of sulfur trioxide passing through the tube during the time at peak temperature (around $6 \mathrm{~g}$ ) was 3-4 times higher than the amount needed in theory for the target mineralogies of the two mixes (around $2.2 \mathrm{~g}$ and $1.4 \mathrm{~g}$, respectively). For these experiments, $\mathrm{C}_{4} \mathrm{AF}$ was chosen as the target stoichiometry for ferrite, as opposed to the $\mathrm{C}_{6} \mathrm{~A}_{2} \mathrm{~F}$ used in the experiments with the laboratory-grade materials. This was done for several reasons. Firstly, the exact stoichiometry of ferrite in $\bar{C} \bar{S} A$ mixes is not well known and both extremes of the solid solution had to be checked. Also, according to the results, the ferrite phase made in the sulfur dioxide plus oxygen atmospheres seemed to be variable, but both the standard used for Rietveld refinement and the data for thermodynamic modelling consider $\mathrm{C}_{4} \mathrm{AF}$.

\section{Characterisation}

The products obtained were characterised by X-ray powder diffraction (XRD) using an Empyrean diffractometer (PANalytical) with strictly monochromatic $\mathrm{CuK} \alpha 1$ radiation $(\lambda=0.154056 \mathrm{~nm})$ at $45 \mathrm{kV}$ and $40 \mathrm{~mA}$. In order to determine the composition of the samples, they were analysed using the Rietveld methodology as implemented in the GSAS software package (Larson and Von Dreele, 2004). Final global optimised parameters included background coefficients, zero-shift 
error, cell parameters and peak shape parameters. Peak shapes were fitted using the pseudo-Voigt function (Thompson et al., 1987) with an asymmetry correction included (Finger et al., 1994). A March-Dollase ellipsoidal preferred orientation correction algorithm (Dollase, 1986) was used when the preferred orientation parameter needed refinement. The crystal structure descriptions for the different phases encountered were given by Cuesta et al. (2013) for orthorhombic ye'elimite, Cuesta et al. (2014) for cubic ye'elimite, Mumme et al. (1995) for $\beta$-belite, Colville and Geller (1971) for ferrite, Louisnathan (1971) for gehlenite, Irran et al. (1997) for ternesite, Hörkner and MüllerBuschbaum (1976) for calcium monoaluminate, Kirfel and Will (1980) for anhydrite and Sasaki et al. (1987) for perovskite.

\section{Thermodynamic modelling}

A thermodynamic model based on Gibbs energy minimisation and a recently compiled high-temperature cement clinker stoichiometric-phase thermodynamic database (Hanein et al., 2015b) was used to supplement the experimental data: raw mix input and experimental conditions included in Table 4 were 'replicated' for the model calculations. The thermodynamic data for ye'elimite and ternesite $\left(\mathrm{C}_{5} \mathrm{~S}_{2} \overline{\mathrm{S}}\right)$ were recently derived by the authors (Hanein et al., 2015a, 2017). The thermodynamic model and compiled database used in this work have been validated in several studies (Galan et al., 2017; Hanein et al., 2015a 2015b, 2016a, 2017). As a means of emulating the furnace operation (continuous counter-current flow) and to maintain constant sulfur dioxide and oxygen partial pressures in the system, the gaseous atmosphere was assumed to be in excess $\left(m_{\text {gas }} \gg m_{\text {solids }}\right)$. Phosphorus pentoxide $\left(\mathrm{P}_{2} \mathrm{O}_{5}\right)$ and manganese oxide $(\mathrm{MnO})$ were neglected in the thermodynamic simulations due to the lack of thermodynamic data for these species and phases containing them. In addition, the database used does not contain thermodynamic data for $\mathrm{C}_{6} \mathrm{~A}_{2} \mathrm{~F} ; \mathrm{C}_{4} \mathrm{AF}$ is the only calcium aluminoferrite for which data are currently available. The model used takes into account both the solids and the atmosphere surrounding them simultaneously. For comparison, only the major phases formed and detected in the XRD measurements of the experimental runs are shown in the model results presented later in the paper. However, the model also accounts for all the species shown in Table 1 (except manganese oxide and phosphorus pentoxide) and all the calculations carried out predicted the conversion of all alkalis to alkali sulfates; magnesium oxide $(\mathrm{MgO})$ appeared to remain unreacted in the thermodynamic calculations.

\section{Results}

Transfer of sulfur between gas and solids

The transfer of sulfur from gas to solid was confirmed to be rapid at $900-1000^{\circ} \mathrm{C}$ and above: calcium oxide reacted readily and completely with mixes of sulfur dioxide and oxygen to form calcium sulfate. Different flow rates of sulfur dioxide:air were used $(0 \cdot 1: 0 \cdot 25, \quad 0 \cdot 434: 1 \cdot 058, \quad 0 \cdot 868: 2 \cdot 116$ and $0 \cdot 217: 0 \cdot 529 \mathrm{~g} / \mathrm{min}$ ) and the experiments were performed using different amounts of calcium oxide in powder form and porous pellets (13 $\mathrm{mm}$ diameter) for different periods of time (from $5 \mathrm{~min}$ to $4 \mathrm{~h}$ ). The formation of $\bar{C} \overline{\mathrm{S}}$ was assessed qualitatively by XRD.

\section{Formation of ye"elimite $\left(\mathrm{C}_{4} \mathrm{~A}_{3} \overline{\mathrm{S}}\right)$}

At $\approx 1200-1300^{\circ} \mathrm{C}, \mathrm{C}_{4} \mathrm{~A}_{3} \overline{\mathrm{S}}$ was formed in sulfur dioxide plus oxygen atmospheres from $30 \mathrm{~g}$ mixes of calcium carbonate and aluminium oxide. Figure 2 shows the XRD pattern following $30 \mathrm{~min}$ reaction at $1220^{\circ} \mathrm{C}$, where the flow rates of sulfur dioxide and air used were $0 \cdot 105$ and $0 \cdot 2624 \mathrm{~g} / \mathrm{min}$, respectively, giving a sulfur dioxide:air ratio of $1: 2 \cdot 5$. Such a high sulfur dioxide concentration did not lead to high yields of

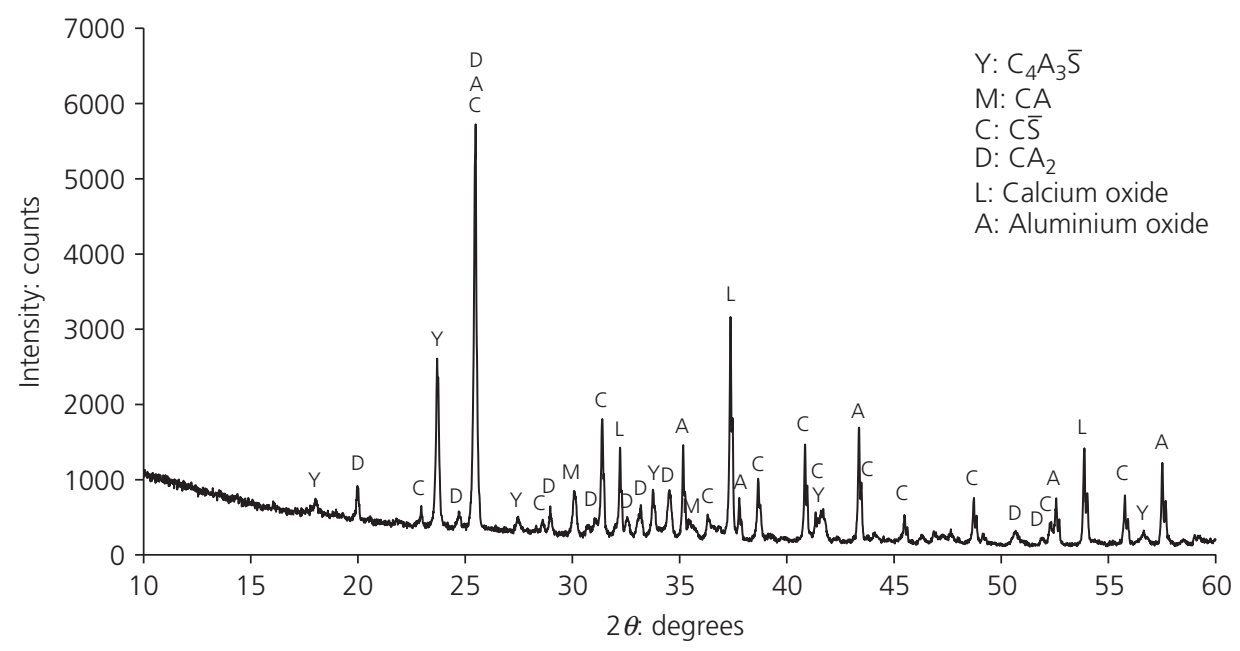

Figure 2. Synthesis of ye'elimite from calcium carbonate and aluminium oxide in an atmosphere of sulfur dioxide plus air (sulfur dioxide: air ratio of $1: 2 \cdot 5$ ) at $1220^{\circ} \mathrm{C}$ after 30 min reaction 


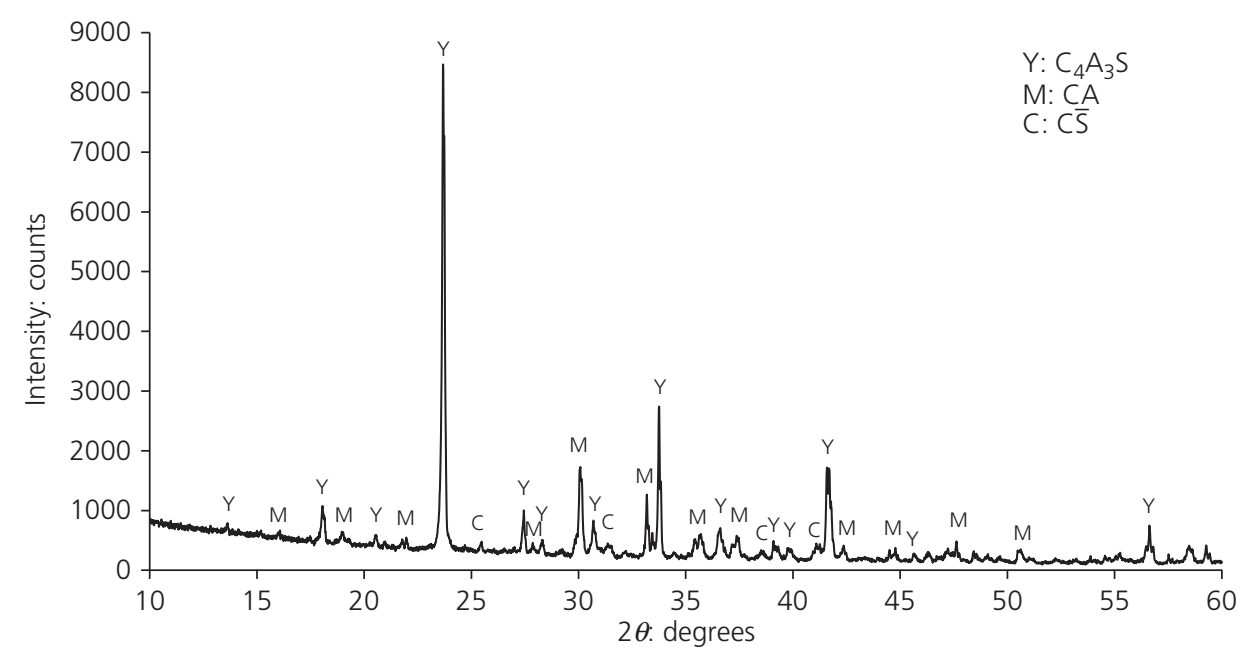

Figure 3. Synthesis of ye'elimite from calcium carbonate and aluminium oxide in an atmosphere of sulfur dioxide plus air (sulfur dioxide: air ratio of $1: 25$ ) at $1220^{\circ} \mathrm{C}$ for $60 \mathrm{~min}$

ye'elimite: anhydrite was formed, leaving unreacted aluminium oxide and calcium oxide coexisting with $\mathrm{CA}_{2}$ and $\mathrm{CA}$. The results cannot be in equilibrium as some phases are known to be incompatible, for example calcium oxide and $\mathrm{CA}_{2}$ (Galan et al., 2017). Reintroducing the sample for another $30 \mathrm{~min}$ in the furnace under the same conditions led to an increase in ye'elimite and a decrease in anhydrite, leaving traces of $\mathrm{CA}_{2}$ and aluminium oxide still present. Further repetition of the same process led to the total disappearance of calcium oxide and aluminium oxide and some increase both in the ye'elimite yield and reduction in the anhydrite with almost constant $\mathrm{CA}_{2}$. After $7 \times 30$ min cycles, the XRD pattern did not change and it was thus considered that the sample had reached its final state.

Flow rates of sulfur dioxide and air of 0.0525 and $1.3122 \mathrm{~g} / \mathrm{min}$, respectively (ratio sulfur dioxide:air of $1: 25$ ) were used for tests of $60 \mathrm{~min}$ duration. Figure 3 shows the result of this synthesis, performed using the same amount of raw materials (stoichiometric amounts of calcium carbonate and aluminium oxide to form $\mathrm{C}_{4} \mathrm{~A}_{3} \overline{\mathrm{S}}$ ) and the same temperature $\left(1220^{\circ} \mathrm{C}\right)$ as the previous experiment, for $60 \mathrm{~min}$. As can be seen from the figure, lower sulfur dioxide partial pressure $\left(10 \times\right.$ dilution) led to higher yields of $\mathrm{C}_{4} \mathrm{~A}_{3} \overline{\mathrm{S}}$, no unreacted raw materials and only small amounts of $\bar{C} \bar{S}$ and CA remaining. These experiments suggest the existence of a threshold in the sulfur dioxide concentration which, if exceeded, favours the reaction of sulfur trioxide with lime to give calcium sulfate, inhibiting the formation of ye'elimite.

\section{Formation of ternesite $\left(\mathrm{C}_{5} \mathrm{~S}_{2} \overline{\mathrm{S}}\right)$}

The formation of $\mathrm{C}_{5} \mathrm{~S}_{2} \overline{\mathrm{S}}$ was investigated in a similar fashion. A mix of calcium carbonate and silicon dioxide was prepared and placed in a boat and reacted at $1220^{\circ} \mathrm{C}$ for $60 \mathrm{~min}$. As with the $\mathrm{C}_{4} \mathrm{~A}_{3} \overline{\mathrm{S}}$ experiments, the reactive sulfur-containing atmosphere was left running for the duration of the experiment. Flow rates of $0 \cdot 25 \mathrm{~g} / \mathrm{min}$ air and $0 \cdot 1 \mathrm{~g} / \mathrm{min}$ sulfur dioxide were used in the initial high sulfur dioxide partial pressure experiment to give a sulfur dioxide:air ratio of 1:2.5. Figure 4 shows that ternesite did not form but, instead, a mixture of belite, anhydrite and unreacted material was produced. The temperature, reaction time and cooling rates of the reaction were altered in attempts to form ternesite but, at this partial pressure, these experiments proved unsuccessful.

As calculations suggested that the sulfur dioxide partial pressure was too high, another experiment was conducted in which the partial pressure of the sulfur dioxide component of the atmosphere was lowered: flow-rates of $0 \cdot 1 \mathrm{~g} / \mathrm{min}$ sulfur dioxide and $2.5 \mathrm{~g} / \mathrm{min}$ air were used to give an air:sulfur dioxide ratio of 25:1. As shown in Figure 5, ternesite was successfully formed at $1075^{\circ} \mathrm{C}$ in the sulfur-containing atmosphere for the first time, in the presence of belite, anhydrite and unreacted lime. This temperature was chosen based on previous work by Pliego-Cuervo and Glasser (1978), who synthesised ternesite in sealed systems using belite and calcium sulfate as reactants. These experiments showed the combined influence of temperature and sulfur dioxide partial pressure on the stability of sulfur-containing phases. The field of stability of ternesite was subsequently mapped by Hanein et al. (2017), who quantitatively demonstrated the necessity of controlling the partial pressures of gas species if ternesite is the desired product.

\section{Synthesis of clinkers using laboratory-grade reactants}

At $1300^{\circ} \mathrm{C}$, clinkers containing ye'elimite, belite and anhydrite were synthesised from mixes of calcium carbonate, silicon dioxide, aluminium oxide and iron oxide using mixes of the 


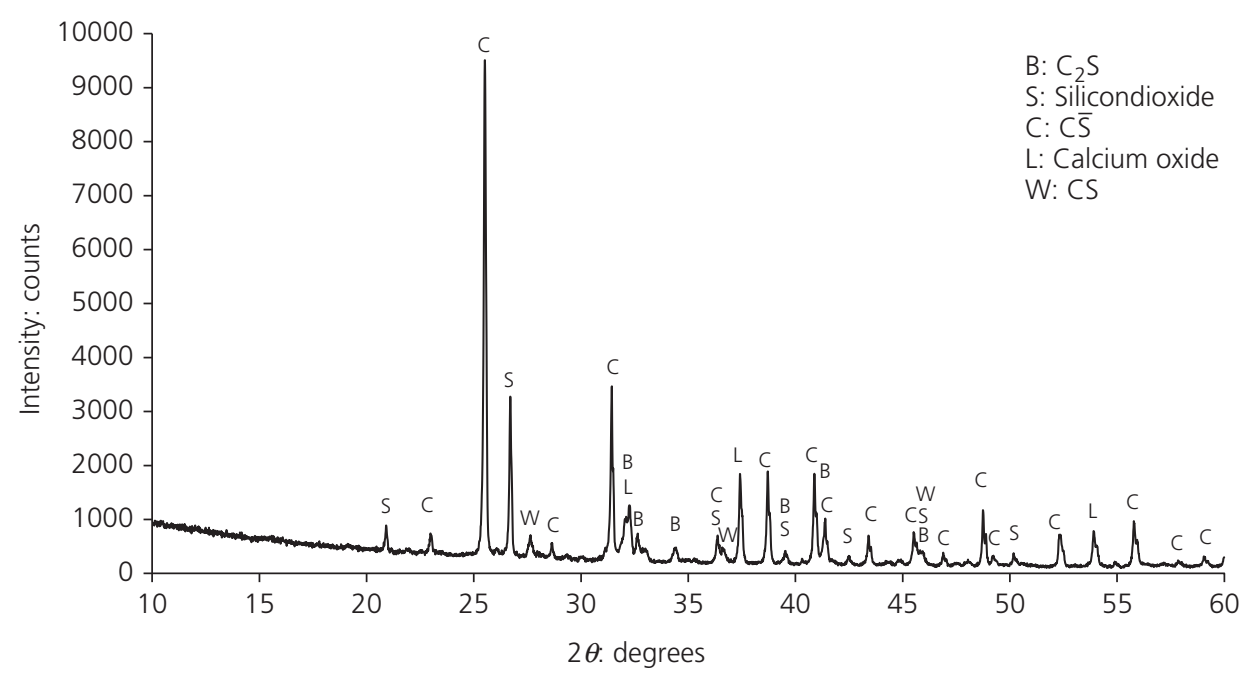

Figure 4. Attempt to synthesise calcium sulfosilicate in an atmosphere of sulfur dioxide plus air (sulfur dioxide:air ratio of 1:2·5) at $1220^{\circ} \mathrm{C}$ for $60 \mathrm{~min}$

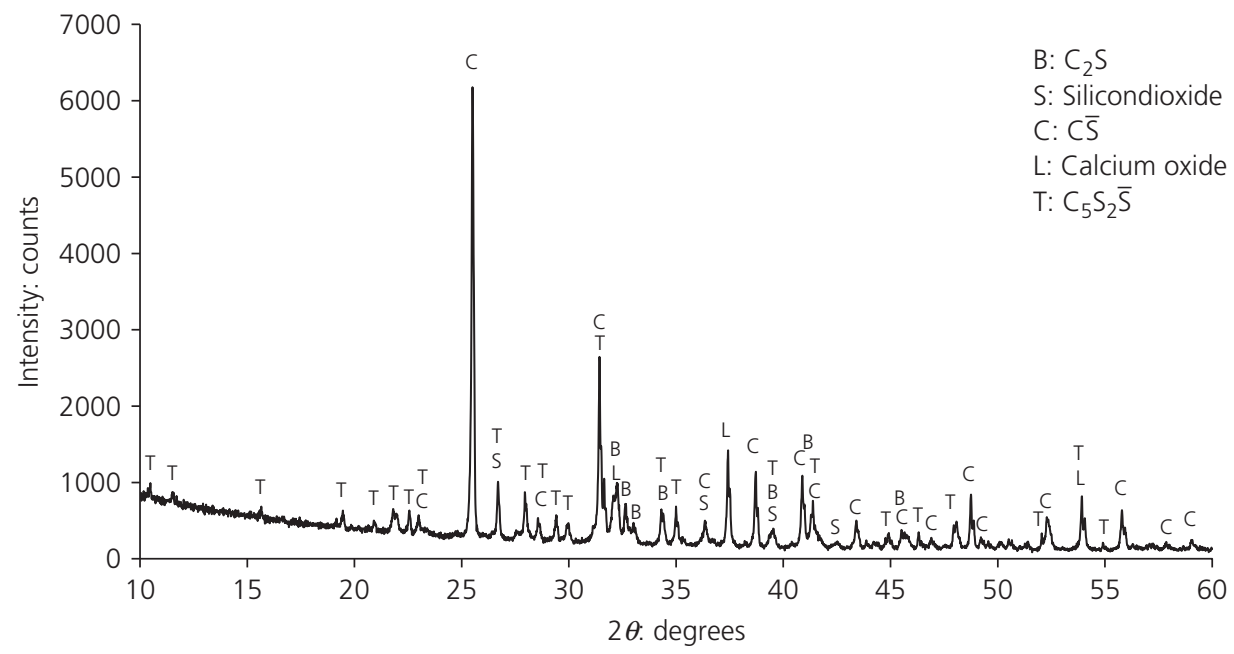

Figure 5. Formation of calcium sulfosilicate from $\mathrm{C}_{2} S$ and $C \bar{S}$ in an atmosphere of sulfur dioxide plus air (sulfur dioxide:air ratio of 1:25) at $1075^{\circ} \mathrm{C}$ for $60 \mathrm{~min}$

reactants in powder form and by pressing these same mixes in the form of $13 \mathrm{~mm}$ diameter pellets. The pellets were $\approx 2 \mathrm{~mm}$ thick. Three different mixes were used in order to obtain different proportions of the phases in the final product. The target compositions are given in Table 2. Figures 6 and 7 show the pellets corresponding to target compositions 1 and 2, respectively. In both cases the pellets were coherent and did not show cracking. However, the pellets with target composition 3, high in silica, crumbled during cooling and only powder could be retrieved.

The results from Rietveld refinement of the XRD patterns of the pellets are shown in Table 5. Mixes 1 and 2 led to the formation of mainly four phases: ye'elimite, belite, anhydrite

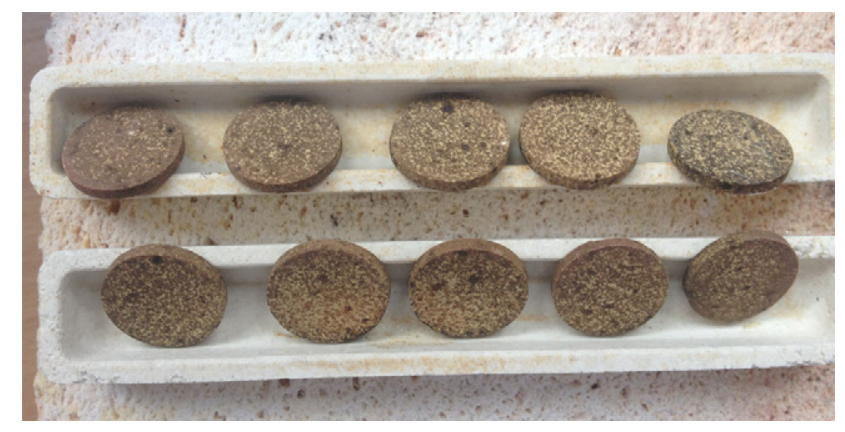

Figure 6. Pellets (13 $\mathrm{mm}$ diameter) with target composition 1 (Table 2) after firing at $1300^{\circ} \mathrm{C}$ for 30 min under sulfur dioxide plus air atmosphere (sulfur dioxide:air ratio of $1: 2.5$ ) 


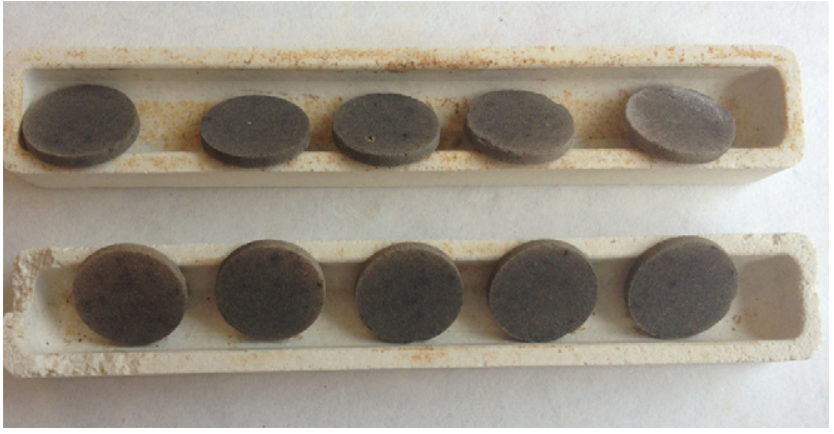

Figure 7. Pellets (13 $\mathrm{mm}$ diameter) with target composition 2 (Table 2) after firing at $1300^{\circ} \mathrm{C}$ for 30 min under sulfur dioxide plus air atmosphere (sulfur dioxide:air ratio of 1:2.5)

and gehlenite $\left(\mathrm{C}_{2} \mathrm{AS}\right)$. In both cases, crystalline ferrite was almost absent. The presence of undesired $\mathrm{C} \overline{\mathrm{S}}$ and $\mathrm{C}_{2} \mathrm{AS}$ can be attributed to kinetic effects but also to the sulfur dioxide partial pressure used, which may have favoured their formation.

Composition 3 gave a very different mineralogy: both $\beta-\mathrm{C}_{2} \mathrm{~S}$ and $\gamma-\mathrm{C}_{2} \mathrm{~S}$ were present, as well as ferrite and tricalcium aluminate. $\mathrm{C} \overline{\mathrm{S}}$ was absent and $\mathrm{C}_{4} \mathrm{~A}_{3} \overline{\mathrm{S}}$ and $\mathrm{C}_{2} \mathrm{AS}$ only appeared in very low percentages. The physical decomposition of pellets, termed 'dusting', is attributed to the volume expansion arising from spontaneous conversion of the high-temperature belite phases to $\gamma-\mathrm{C}_{2} \mathrm{~S}$ in the course of cooling.

Table 6 shows the results obtained from Rietveld analysis for the clinkers synthesised using laboratory-grade reactants including calcium sulfate (conditions shown in Table 3).

At a constant temperature of $1280^{\circ} \mathrm{C}$, a drastic effect was observed when diluting the sulfur dioxide from a sulfur
Advances in clinkering technology of

calcium sulfoaluminate cement

Galan, Elhoweris, Hanein, Bannerman and

Glasser dioxide:air ratio of 1:2.5 to 1:25 (experiments 1 and 2, respectively, in Table 6), not only on the formation of ye'elimite but also on the belite. High concentrations of sulfur dioxide shifted the equilibrium away from belite to mixtures of $\mathrm{C} \overline{\mathrm{S}}$ and $\mathrm{C}_{2} \mathrm{AS}$. A further reduction in the sulfur dioxide partial pressure (ratios sulfur dioxide:air ratios of 1:50 and 1:100 in experiments 3 and 4 in Table 6) did not lead to significant changes in the final compositions. The remaining percentages of $\mathrm{C}_{2} \mathrm{AS}$ and $\mathrm{CS}$ were attributed to kinetic effects: once $\mathrm{C}_{2} \mathrm{AS}$ and $\mathrm{CS}$ were formed in quantity, $120 \mathrm{~min}$ did not seem to be sufficient to completely shift compositions towards $\mathrm{C}_{2} \mathrm{~S}$ and $\mathrm{C}_{4} \mathrm{~A}_{3} \overline{\mathrm{S}}$.

Lower temperatures also had an impact on the final compositions, especially at the lower sulfur dioxide partial pressure conditions (experiment 5 in Table 6 , at $1230^{\circ} \mathrm{C}$ and 1:50 sulfur dioxide:air ratio), making it even more difficult to reach the target compositions by reacting $\mathrm{C} \overline{\mathrm{S}}$ and $\mathrm{C}_{2} \mathrm{AS}$.

The effect of the gas flow rate is also shown in the results of experiments 2 and 9. Similar temperatures $\left(1280^{\circ} \mathrm{C}\right.$ and $1270^{\circ}$ $\mathrm{C}$, respectively) and partial pressures (sulfur dioxide:air ratio of $1: 25$ ) but different gas flow rates (sulfur dioxide:air flow rates of $0 \cdot 105: 2 \cdot 63$ and $0 \cdot 088: 2 \cdot 204 \mathrm{~g} / \mathrm{min}$, respectively) produced different results. The lower flow rate promoted the formation of $\mathrm{C}_{4} \mathrm{~A}_{3} \overline{\mathrm{S}}$ and $\mathrm{C}_{2} \mathrm{~S}$ : the faster the gases passed over the solid reactants, the more this reaction was suppressed.

Compositions with higher ye'elimite content (around 60\%) could be achieved at temperatures as low as $1200^{\circ} \mathrm{C}$ (experiment 10 in Table 6); increasing the temperature to $1250^{\circ} \mathrm{C}$ led to an increase in both ye'elimite and belite contents (experiment 11 in Table 6).

The absence of ferrite in some clinkers could be attributed to the poorly crystalline ferrite, not 'visible' by XRD, the possible inclusion of some iron (probably not exceeding a few $\mathrm{wt}^{\mathrm{T}} \%$ ) in

Table 5. Rietveld analysis results of clinkers synthesised from laboratory grades of calcium carbonate, silicon dioxide, aluminium oxide and iron oxide: experimental conditions shown in Table 2

\begin{tabular}{|c|c|c|c|c|c|c|c|c|c|c|}
\hline \multirow[b]{2}{*}{ Experiment } & \multirow[b]{2}{*}{ Target mineralogy } & \multicolumn{8}{|c|}{ Output mineralogy: $w t \%^{a}$} & \multirow[b]{2}{*}{ WRp: $\%^{\mathrm{b}}$} \\
\hline & & $\mathrm{C}_{4} \mathrm{~A}_{3} \overline{\mathrm{S}}$ & $\mathrm{C}_{2} \mathrm{~S}$ & $C \bar{S}$ & $\mathrm{C}_{2} \mathrm{AS}$ & $\mathrm{C}_{4} \mathrm{AF}$ & $\mathrm{S}$ & $\mathrm{C}_{3} \mathrm{~A}$ & $\mathrm{C}_{12} \mathrm{~A}_{7}$ & \\
\hline \multirow[t]{2}{*}{1} & $60 \mathrm{wt} \% \mathrm{C}_{4} \mathrm{~A}_{3} \overline{\mathrm{S}}$ & O 20 & $\alpha^{\prime} 1$ & 23 & 26 & 1 & - & - & - & $5 \cdot 28$ \\
\hline & $\begin{array}{l}20 w t \% C_{2} S \\
20 w t \% C_{6} A_{2} F\end{array}$ & C 28 & $\beta 2$ & - & - & - & - & - & - & - \\
\hline \multirow[t]{2}{*}{2} & $40 w t \% C_{4} A_{3} S$ & O 15 & $\alpha^{\prime} 2$ & 18 & 21 & 1 & - & - & - & 4.99 \\
\hline & $\begin{array}{l}40 w t \% C_{2} S \\
20 w t \% C_{6} A_{2} F\end{array}$ & C 23 & $\beta 19$ & - & - & - & - & - & - & - \\
\hline \multirow[t]{2}{*}{3} & $20 w t \% C_{4} A_{3} S$ & 02 & $\beta 25$ & - & 1 & 28 & 4 & 20 & 1 & $5 \cdot 48$ \\
\hline & $\begin{array}{l}60 w t \% C_{2} S \\
20 w t \% C_{6} A_{2} F\end{array}$ & & $\gamma 18$ & - & - & - & - & - & - & - \\
\hline
\end{tabular}

aThe polymorphs of $C_{4} A_{3} \bar{S}$ and $C_{2} S$ are shown: $O$ and $C$ stand for orthorhombic and cubic ye'elimite, respectively, and $\alpha^{\prime}, \beta$ and $\gamma$ are the three polymorphs of $C_{2} S$. $\mathrm{C}$ represents calcium oxide, A represents aluminium oxide, $\overline{\mathrm{S}}$ represents sulfur trioxide, $\mathrm{S}$ represents sulfur dioxide and $\mathrm{F}$ represents iron oxide (Fe $\mathrm{O}_{3}$ )

${ }^{\mathrm{b}} \mathrm{WR}$ is the weighted-profile $R$ factor 
Table 6. Rietveld analysis results of clinkers synthesised from laboratory grades of calcium carbonate, silicon dioxide, aluminium oxide, iron oxide and calcium sulfate: experimental conditions shown in Table 3. The 'Target mineralogy' data apply to multiple experiments

\begin{tabular}{|c|c|c|c|c|c|c|c|c|c|c|c|}
\hline \multirow[b]{2}{*}{ Experiment } & \multirow[b]{2}{*}{ Target mineralogy } & \multicolumn{9}{|c|}{ Output mineralogy: wt $\%^{a}$} & \multirow[b]{2}{*}{ wRp: \% } \\
\hline & & $\mathrm{C}_{4} \mathrm{~A}_{3} \overline{\mathrm{S}}$ & $\beta-C_{2} \mathrm{~S}$ & $\mathrm{CS}$ & $\mathrm{C}_{2} \mathrm{AS}$ & $\mathrm{C}_{5} \mathrm{~S}_{2} \overline{\mathrm{S}}$ & CA & $\mathrm{C}_{4} \mathrm{AF}$ & C & $\mathrm{S}$ & \\
\hline \multirow[t]{2}{*}{1} & $30 w t \% C_{4} A_{3} \bar{S}$ & 01 & - & 57 & 38 & - & - & - & - & - & 5.68 \\
\hline & $60 \mathrm{wt} \% \mathrm{C}_{2} \mathrm{~S}$ & C 4 & - & - & - & - & - & - & - & - & - \\
\hline \multirow[t]{2}{*}{2} & $10 w t \% \mathrm{C}_{6} \mathrm{~A}_{2} \mathrm{~F}$ & O 17 & 33 & 16 & 22 & - & - & - & - & - & $5 \cdot 57$ \\
\hline & & C 12 & - & - & - & - & - & - & - & - & - \\
\hline \multirow[t]{2}{*}{3} & & O 19 & 37 & 12 & 19 & - & - & - & - & - & $4 \cdot 72$ \\
\hline & & C 13 & - & - & - & - & - & - & - & - & - \\
\hline \multirow[t]{2}{*}{4} & & O 15 & 33 & 11 & 21 & - & - & - & - & - & 5.74 \\
\hline & & C 19 & - & - & - & - & - & - & - & - & - \\
\hline \multirow[t]{2}{*}{5} & & 09 & 13 & 41 & 13 & 4 & 7 & 1 & - & 2 & $8 \cdot 33$ \\
\hline & & C 10 & - & - & - & - & - & - & - & - & - \\
\hline \multirow[t]{2}{*}{6} & & O 24 & 35 & 12 & 5 & 2 & - & 4 & 4 & 2 & $5 \cdot 23$ \\
\hline & & C 11 & - & - & - & - & - & - & - & - & - \\
\hline \multirow[t]{2}{*}{7} & & O 23 & 21 & 24 & 4 & 8 & - & 3 & 6 & 4 & $6 \cdot 00$ \\
\hline & & C 8 & - & - & - & - & - & - & - & - & - \\
\hline \multirow[t]{2}{*}{8} & & O 15 & 32 & 21 & 14 & 4 & - & - & - & - & $5 \cdot 89$ \\
\hline & & C 14 & - & - & - & - & - & - & - & - & - \\
\hline \multirow[t]{2}{*}{9} & & O 27 & 40 & 13 & 5 & - & - & - & - & - & $5 \cdot 70$ \\
\hline & & C16 & - & - & - & - & - & - & - & - & - \\
\hline \multirow[t]{2}{*}{10} & $60 w t \% C_{4} A_{3} \bar{S}$ & O 43 & 8 & 17 & 2 & 4 & 4 & 2 & 4 & - & $5 \cdot 81$ \\
\hline & $30 w t \% C_{2} S$ & C 15 & - & - & - & - & - & - & - & - & - \\
\hline 11 & $10 w t \% \mathrm{C}_{6} \mathrm{~A}_{2} \mathrm{~F}$ & O 63 & 14 & 16 & 7 & - & - & - & - & - & $9 \cdot 22$ \\
\hline
\end{tabular}

aThe polymorphs of $C_{4} A_{3} \bar{S}$, orthorhombic (O) and cubic (C), are shown. All $C_{2} S$ formed in these experiments was $\beta$ - $C_{2} S$

ye'elimite (Touzo et al., 2013) and the limitations of XRD in detecting small amounts of phases.

\section{Synthesis of clinkers using commercial-grade reactants}

Tables 7 and 8 respectively show the results of Rietveld analysis and the thermodynamic modelling output of clinkers made with commercial-grade raw materials (conditions shown in Table 4).

Dilution of the sulfur dioxide from sulfur dioxide:air ratios of 1:25 (experiments 1 and 2 in Table 7) to 1:100 (experiments 3 and 4 in Table 7) led to a significant increase in ye'elimite and belite. In addition, the yields at $1300^{\circ} \mathrm{C}$ were notably higher than at $1250^{\circ} \mathrm{C}$ (experiments $1-4$ in Table 7).

These experiments indirectly show the effect of the presence of impurities in the raw materials. Impurities affect the stability and formation of the phases, leading to different results and different effects of temperature and sulfur dioxide partial pressure. The mineralogical evolution with time can be observed from the results of experiments 5-7 in Table 7: at $1300^{\circ} \mathrm{C}$ and a sulfur dioxide:air ratio of 1:100, equilibrium seems to shift towards the formation of ye'elimite and belite with slow the disappearance of gehlenite and anhydrite.

According to the model predictions, the conditions used in experiments 2, 4 and 5-7 would lead to the target compositions. The reasons why these were not actually achieved are likely due to kinetic limitations, the ferrite not being 'visible' with XRD and possibly the cooling rate, which may have favoured the formation of anhydrite and gehlenite as opposed to ye'elimite and belite. It must also be noted that the model does not account for solid solutions (or liquid solutions) and therefore cannot predict the formation of entropy-stabilised phases such as ye'elimite with iron substitution or various aluminoferrite compositions.

The formation of ternesite was predicted in four of the compositions (2, 3, 8 and 9 in Table 8 ) but only detected experimentally in two (experiments 3 and 8 in Table 7). This can be understood by looking at the temperatures and partial pressures that were used. Comparing experiments 2 and 3 in Table 4, both were carried out at sulfur dioxide:air ratios of 1:100, but at different temperatures. Ternesite could be seen in the experiment at $1250^{\circ} \mathrm{C}$, but a temperature of $1300^{\circ} \mathrm{C}$ appears to be too high for ternesite to stabilise. In experiments 8 and 9 in Table 4, both performed at $1275^{\circ} \mathrm{C}$, the lower sulfur dioxide partial pressure (i. e. 1:100 sulfur dioxide:air ratio) favoured the formation and stabilisation of ternesite as opposed to the 1:50 ratio. Even though, under ideal conditions, ternesite would form in all cases, in reality too high temperatures and too high partial pressures make it more difficult for ternesite to be stabilised.

\section{Discussion}

At present, designing and implementing an 'optimum' $\mathrm{C} \overline{\mathrm{S}} \mathrm{A}$ clinker is arguably more difficult than producing a Portland 
Table 7. Rietveld analysis results of clinkers synthesised from commercial-grade raw materials clay, bauxite and limestone: experimental conditions shown in Table 4. The 'Target mineralogy' data apply to multiple experiments

\begin{tabular}{|c|c|c|c|c|c|c|c|c|}
\hline \multirow[b]{2}{*}{ Experiment } & \multirow[b]{2}{*}{ Target mineralogy } & \multicolumn{6}{|c|}{ Output mineralogy: wt $\%^{a}$} & \multirow[b]{2}{*}{ wRp: \% } \\
\hline & & $\mathrm{C}_{4} \mathrm{~A}_{3} \overline{\mathrm{S}}$ & $\mathrm{C}_{2} \mathrm{~S}$ & $C \bar{S}$ & $\mathrm{C}_{2} \mathrm{AS}$ & CT & $\mathrm{C}_{5} \mathrm{~S}_{2} \overline{\mathrm{S}}$ & \\
\hline \multirow[t]{2}{*}{1} & $36 w t \% C_{4} A_{3} \bar{S}$ & 01 & - & 64 & 31 & 1 & - & $9 \cdot 46$ \\
\hline & $32 w t \% C_{2} S$ & C 4 & - & - & - & - & - & - \\
\hline \multirow[t]{2}{*}{2} & $9 \mathrm{wt} \% \mathrm{C}_{4} \mathrm{AF}$ & 08 & $\beta 4$ & 48 & 25 & - & 1 & $9 \cdot 30$ \\
\hline & $23 w t \% C \bar{S}$ & C 13 & $\alpha^{\prime} 2$ & - & - & - & - & - \\
\hline \multirow[t]{2}{*}{3} & & O 20 & $\beta 11$ & 29 & 4 & 2 & 11 & $6 \cdot 79$ \\
\hline & & C 17 & $\alpha^{\prime} 7$ & - & - & - & - & - \\
\hline \multirow[t]{2}{*}{4} & & O 30 & $\beta 23$ & 22 & - & 1 & 0 & $5 \cdot 63$ \\
\hline & & C 16 & $\alpha^{\prime} 8$ & - & - & - & - & - \\
\hline \multirow[t]{2}{*}{5} & 34 wt $\% C_{4} A_{3} \bar{S}$ & O 22 & $\beta 28$ & 23 & - & 5 & - & 8.46 \\
\hline & $42 w t \% C_{2} S$ & C 20 & $\alpha^{\prime} 3$ & & - & - & - & - \\
\hline \multirow[t]{2}{*}{6} & $11 w t \% C_{4} A F$ & O 10 & $\beta 23$ & 27 & 3 & 3 & - & 8.63 \\
\hline & 12 wt $\%$ C $\bar{S}$ & C 32 & $\alpha^{\prime} 3$ & - & - & - & - & - \\
\hline \multirow[t]{2}{*}{7} & & O 13 & $\beta 19$ & 32 & 9 & 1 & 2 & $6 \cdot 93$ \\
\hline & & C 23 & $\alpha^{\prime} 2$ & - & - & - & - & - \\
\hline \multirow[t]{2}{*}{8} & & 08 & $\beta 9$ & 27 & 11 & 1 & 18 & $6 \cdot 60$ \\
\hline & & C 25 & - & - & - & - & - & - \\
\hline \multirow[t]{2}{*}{9} & & 01 & - & 59 & 39 & - & - & $10 \cdot 62$ \\
\hline & & C 1 & - & - & - & - & - & - \\
\hline
\end{tabular}

The polymorphs of $\mathrm{C}_{4} \mathrm{~A}_{3} \overline{\mathrm{S}}$ and $\mathrm{C}_{2} \mathrm{~S}$ are shown: $\mathrm{O}$ and $\mathrm{C}$ stand for orthorhombic and cubic ye'elimite, respectively, and $\alpha^{\prime}$ and $\beta$ are the polymorphs of $\mathrm{C}_{2} \mathrm{~S}$. CT stands for perovskite (calcium titanate $\mathrm{CaTiO}_{3}$ )

Table 8. Model predictions for the clinker compositions made with commercial-grade clay, bauxite and limestone. The temperatures and gas atmospheres used for the simulations are detailed in Table 4

\begin{tabular}{|c|c|c|c|c|c|c|c|c|}
\hline \multirow[b]{2}{*}{ Composition } & \multicolumn{8}{|c|}{ Model output: wt $\%$ using raw materials } \\
\hline & $\mathrm{C}_{4} \mathrm{~A}_{3} \overline{\mathrm{S}}$ & $\mathrm{C}_{2} \mathrm{~S}$ & $\mathrm{CS}$ & $\mathrm{C}_{4} \mathrm{AF}$ & $\mathrm{C}_{5} \mathrm{~S}_{2} \overline{\mathrm{S}}$ & $\mathrm{CT}$ & $C F(L)^{a}$ & Magnesium oxide \\
\hline 1 & $38 \cdot 7$ & - & $12 \cdot 8$ & - & $44 \cdot 5$ & 1.6 & $2 \cdot 2$ & 0.2 \\
\hline 2 & $37 \cdot 2$ & $32 \cdot 4$ & 23.5 & $5 \cdot 0$ & - & $1 \cdot 6$ & - & 0.2 \\
\hline 3 & $37 \cdot 2$ & - & $10 \cdot 7$ & $5 \cdot 0$ & $45 \cdot 2$ & 1.6 & - & $0 \cdot 2$ \\
\hline 4 & $37 \cdot 2$ & $32 \cdot 4$ & $23 \cdot 5$ & $5 \cdot 0$ & - & 1.6 & - & $0 \cdot 2$ \\
\hline 5 & $35 \cdot 6$ & $42 \cdot 0$ & $14 \cdot 0$ & $6 \cdot 6$ & & $1 \cdot 5$ & - & 0.3 \\
\hline 6 & $35 \cdot 6$ & $42 \cdot 0$ & $14 \cdot 0$ & $6 \cdot 6$ & & $1 \cdot 5$ & - & 0.3 \\
\hline 7 & $35 \cdot 6$ & $42 \cdot 0$ & $14 \cdot 0$ & $6 \cdot 6$ & & $1 \cdot 5$ & - & 0.3 \\
\hline 8 & $35 \cdot 6$ & $6 \cdot 4$ & - & $6 \cdot 6$ & $49 \cdot 6$ & 1.5 & - & 0.3 \\
\hline 9 & $35 \cdot 6$ & $6 \cdot 4$ & - & $6 \cdot 6$ & $49 \cdot 6$ & 1.5 & - & 0.3 \\
\hline
\end{tabular}

aL represents liquid state

cement clinker. For example, the 'optimum' clinker mineralogy is not known at present. Should ternesite be present and, if so, how much? Can the polymorphism of belite be controlled so as to reproduce a reactive clinker with fast strength gain? How are the economics of the raw materials associated with clinker mineralogy? How do the clinker phases react with water and with each other to produce dense and durable matrices? Many questions remain unanswered.

Another complication arising is the presence of an important sulfur cycle in the course of clinkering, which can affect mineralogy. These dependencies, weak for Portland cement, become crucial in making $\mathrm{C} \overline{\mathrm{S}} \mathrm{A}$ cements. The concept of using a reactive atmosphere to facilitate reaction kinetics and control quantitative clinker mineralogy is critical, but has not been well explored in respect of C $\bar{S} A$ cement clinkering.

It is known that gas-solid reactions are important in a range of problems, for example in Portland cement clinkering where the cycle of alkali circulation via the vapour phase may lead to condensation in the cooler zones of (potassium, sodium) sulfates on the clinker and these, in turn, affect early hydration and set. However, the main oxide components of Portland cement are relatively involatile and the vapour phase composition is relatively unimportant to the circulation of the main oxides. However, cycles involving the transfer of sulfur species assume much greater importance in the course of clinkering $\bar{C} \bar{S} A$ formulations where they control mass and 
energy balances. Both $\mathrm{C}_{4} \mathrm{~A}_{3} \overline{\mathrm{S}}$ and $\mathrm{C}_{5} \mathrm{~S}_{2} \overline{\mathrm{S}}$ have definite limits of thermodynamic stability that need to be formulated in terms of composition, temperatures and fugacities of both sulfur dioxide and oxygen. The authors' approach to process development and optimisation - combining thermodynamic calculation with experimentally derived data - is being brought to maturity to guide and enhance clinker process development quantitatively in order to control clinker mineralogy.

Many commentators have expressed doubts that gas fugacities (equated here with partial pressures) can be controlled in a rotary kiln. While this may be true in general, special circumstances arise in the formation of $\mathrm{C} \overline{\mathrm{S}} \mathrm{A}$ clinkers that make such control relatively easy to achieve. For example, conventional kilns consume the oxygen components of air with the result that the atmosphere in the burning zone has around $1-4 \%$ free oxygen - typically an order of magnitude less than air. If the oxygen pressure is allowed to drop below that range, locally reducing conditions are generated that affect clinker quality; for example, ferric iron is reduced to ferrous iron. Moreover, sulfur, if present, is chemically reduced to sulphide, and carbon monoxide increasingly appears in the exit gases. These processes are undesirable, so free oxygen is always present in excess in combustion gas. On the other hand, if oxygen partial pressures are allowed to rise, the thermal economy decreases as excess air is unnecessarily heated. Even if oxygen-enriched gas is used, the same set of restrictions applies. Broadly speaking, it can be assumed that these considerations will also apply to C $\bar{S} A$ production. Thus, it can be assumed that the oxygen partial pressure will lie within a narrow range to optimise the clinkering process.

Sulfur species at elevated temperatures are dominated by sulfur dioxide and its partial pressure is fixed by temperature and by the sulfur content of the raw meal and fuel. As an approximation, the vapour pressure of sulfur dioxide in equilibrium with the clinker phases, for example anhydrite and ye'elimite, can be used to fix the minimum numerical value of the partial pressures necessary to stabilise these phases against evaporation. However, the actual pressure may significantly exceed that minimum, as for example is likely to occur in the course of combusting sulfur-rich fuels or when elemental sulfur is injected into the kiln to supply part of the thermal energy.

Three regimes in clinkering $\mathrm{C} \overline{\mathrm{S}} \mathrm{A}$ compositions can thus be distinguished - (a) a regime with low partial pressure of sulfur dioxide in which the raw meal loses sulfur in order to saturate the kiln atmosphere, $(b)$ a regime that is essentially neutral and no significant loss or gain of sulfur occurs between solids and the atmosphere and (c) a regime mainly of higher sulfur dioxide pressures in which sulfur, effectively as 'sulfur trioxide', is transferred from the atmosphere to the solid. In order for regime (c) to operate, excess oxygen has to be present because, as noted, the transfer of sulfur from vapour to solid also involves an oxidation of the sulfur from sulfur(IV) to sulfur (VI). However, this condition is readily achieved by an excess of oxygen in the kiln atmosphere.

Despite the limitations of the experimental setup, it was successfully proven that the transfer of sulfur dioxide and oxygen gas to clinkering solids to form $\mathrm{C} \overline{\mathrm{S}} \mathrm{A}$ clinkers occurs rapidly and efficiently under normal operating conditions. It was also found that clinkering temperatures tend to fall within a narrow range. At temperatures below $\approx 1230^{\circ} \mathrm{C}$, reaction kinetics are too slow to achieve complete reaction in the normal residence time in the hot zone (around 20-60 min). On the other hand, if the production of ternesite is desired, which decomposes above an estimated $1298^{\circ} \mathrm{C}$ (Gutt and Smith, 1967), clinkering temperatures cannot exceed this limit and the sulfur pressures need to be maintained within the limits determined by Hanein et al. (2017). If these limits are observed, ternesite-rich clinkers can be made in a single-stage operation. However, ternesite can only be considered a desirable clinker mineral if, in clinker, its reactions with other minerals and water lead to rapid strength gain; at present, this is not fully assured.

Clinkers containing ye'elimite have similar restrictive ranges where kinetics and equilibrium allow it to form stably, but these limits are in general somewhat less restrictive than those for ternesite. Extensive melting occurs above $\approx 1320^{\circ} \mathrm{C}$ so, depending on the target mineralogy, clinkering temperatures will also lie in a narrow band between about 1250 and $1320^{\circ} \mathrm{C}$. The other key variable, the partial pressure of sulfur dioxide, greatly affects the mineralogy of the clinkers: at a given temperature (around $1250-1300^{\circ} \mathrm{C}$ ), a threshold in sulfur dioxide partial pressure exists above which $\mathrm{C} \overline{\mathrm{S}}$ and $\mathrm{C}_{2} \mathrm{AS}$ are more likely to form than $\mathrm{C}_{4} \mathrm{~A}_{3} \overline{\mathrm{S}}$ and $\mathrm{C}_{2} \mathrm{~S}$.

Under less secure control are the rates of sulfur transfer and their relation to the state or condition of the gas-solid surface available for exchange. These are functions of, among other factors, kiln size, gas flow rates and counter-current solid flow rates, as well as the total mass of transferrable components. As such, these factors are probably specific to specific equipment and cannot be readily calculated without process data.

By combining technical and thermodynamic limits, it is possible to control a kiln atmosphere simply by controlling the sulfur content of the fuel and raw mix and ensuring an excess of oxygen. The knowledge gained from these experiments and calculations (i.e. the influence of temperature and partial pressures of the gaseous components) partially informed the pilotplant trials at Ibutec, Weimar, Germany, reported by Hanein et al. (2016a).

Another important aspect of this work - controlling the polymorphism and reactivity of belite - is still work in progress (Elhoweris et al., unpublished). In addition, hydration studies are needed to determine the properties of the resulting binders 
at all ages. The correlation of clinker mineralogy with cementing properties is under investigation (Jen et al., 2017).

\section{Conclusions}

The experiments reported here showed that sulfur dioxide and oxygen in vapour are readily transferred to calcium aluminates and silicates, thereby combining much of the sulfur. Understanding of the physical chemistry of the process enables control over clinker phase composition and avoids the production of free lime arising from the decomposition of anhydrite and aluminates. The method described emphasises mass gains as opposed to the more usual mass losses, which gives greater freedom to the design of $\mathrm{C} \overline{\mathrm{S}} \mathrm{A}$ clinkers with optimised properties, and utilises sulfur-containing fuel whose heat of combustion enables decreased consumption of hydrocarbon fuel and lowered carbon dioxide emissions. Thermodynamic modelling has proven to be an invaluable tool with which to simulate, evaluate and optimise novel cement compositions.

\section{Acknowledgement}

The authors gratefully acknowledge the financial support provided by the Gulf Organisation for Research and Development (GORD), Qatar, through University of Aberdeen research grant number ENG016RGG11757.

\section{REFERENCES}

Bale CW, Chartrand P, Degterov SA et al. (2002) FactSage thermochemical software and databases. Calphad: Computer Coupling of Phase Diagrams and Thermochemistry 26(2): 189-228.

Barry TI and Glasser FP (2000) Calculations of Portland cement clinkering reactions. Advances in Cement Research 12(1): 19-28, http://dx.doi.org/10.1680/adcr.2000.12.1.19.

Colville AA and Geller S (1971) The crystal structure of brownmillerite, $\mathrm{Ca}_{2} \mathrm{FeA}_{1} \mathrm{O}_{5}$. Acta Crystallographica Section B 27 2311-2315.

Cuesta A, De La Torre AG, Losilla ER et al. (2013) Structure, atomistic simulations, and phase transition of stoichiometric yeelimite. Chemistry of Materials 25(9): 1680-1687.

Cuesta A, De La Torre AG, Losilla ER, Santacruz I and Aranda MAG (2014) Pseudocubic crystal structure and phase transition in doped ye'elimite. Crystal Growth and Design 14(10): $5158-5163$.

Davies RH, Dinsdale AT, Gisby JA, Robinson JAJ and Martin SM (2002) MTdata - thermodynamic and phase equilibrium software from the national physical laboratory. Calphad: Computer Coupling of Phase Diagrams and Thermochemistry 26(2): 229-271.

Dollase WA (1986) Correction of intensities of preferred orientation in powder diffractometry: application of the March-model. Journal of Applied Crystallography 19(4): 267-272.

Finger LW, Cox DE and Jephcoat AP (1994) Correction for powder diffraction peak asymmetry due to axial divergence. Journal of Applied Crystallography 27(6): 892-900.

Galan I, Glasser FP, Elhoweris A, Tully S and Murdoch A (2014) Novel process for calcium sulfoaluminate production. Proceedings of the 34th Cement and Concrete Science Conference, Sheffield, UK (Bernal SA and Provis J (eds)), pp. 125-128.

Galan I, Hanein T, Elhoweris A, Bannerman MN and Glasser FP (2017) Phase compatibility in the system $\mathrm{CaO}-\mathrm{SiO}_{2}-\mathrm{Al}_{2} \mathrm{O}_{3}-\mathrm{SO}_{3}-\mathrm{Fe}_{2} \mathrm{O}_{3}$ and the effect of partial pressure on phase stability. Industrial \& Engineering Chemistry Research 56(9): 2341-2349.

Gartner E (2004) Industrially interesting approaches to 'low- $\mathrm{CO}_{2}$ ' cements. Cement and Concrete Research 34(9): 1489-1498.

Gartner E and Hirao H (2015) A review of alternative approaches to the reduction of $\mathrm{CO}_{2}$ emissions associated with the manufacture of the binder phase in concrete. Cement and Concrete Research 78A: 126-142, https://doi.org/10.1016/j.cemconres.2015.04.012.

Gartner EM and MacPhee DE (2011) A physico-chemical basis for novel cementitious binders. Cement and Concrete Research 41(7) 736-749.

Gutt W and Smith MA (1967) Studies of the sub-system CaO-CaO. $\mathrm{SiO}_{2}-\mathrm{CaSO}_{4}$. Transactions of the British Ceramic Society 66: $557-567$

Hanein T, Elhoweris A, Galan I, Glasser FP and Bannerman M (2015a) Thermodynamic data of ye'elemite $\left(\mathrm{C}_{4} \mathrm{~A}_{3} \overline{\mathrm{S}}\right)$ for cement clinker equilibrium calculations. Proceedings of the 35th Cement and Concrete Science Conference, Aberdeen, UK (Imbabi M and Glasser FP (eds)). Centre for Innovative Building Materials and Technologies, Aberdeen, UK.

Hanein T, Glasser FP and Bannerman M (2015b) Thermodynamics of Portland cement clinkering. In Proceedings of the 14th International Congress on the Chemistry of Cement (ICCC) (Shi C and Yao Y (eds)). China building materials academy, Beijing, China.

Hanein T, Galan I, Elhoweris A et al. (2016a) Production of belite calcium sulfoaluminate cement using sulfur as a fuel and as a source of clinker sulfur trioxide: pilot kiln trial. Advances in Cement Research 28(10): 643-653, http://dx.doi.org/10.1680/jadcr. 16.00018 .

Hanein T, Imbabi MS, Glasser FP and Bannerman MN (2016b) Lowering the carbon footprint and energy consumption of cement production: a novel calcium sulfoaluminate cement production process. Proceedings of the 1st International Conference on Grand Challenges in Construction Materials (De Fillipo J and Sant G (eds)). University of California, Los Angeles, CA, USA.

Hanein T, Galan I, Glasser FP et al. (2017) Stability of ternesite and the production at scale of ternesite-based clinkers. Cement and Concrete Research 98: 91-100, https://doi.org/10.1016/j.cemconres. 2017.04.010.

Hökfors B, Eriksson M and Viggh E (2014) Modelling the cement process and cement clinker quality. Advances in Cement Research 26(6): 311-318, http://dx.doi.org/10.1680/ adcr.13.00050.

Hökfors B, Boström D, Viggh E and Backman R (2015) On the phase chemistry of Portland cement clinker. Advances in Cement Research 27(1): 50-60, http://dx.doi.org/10.1680/adcr. 13.00071.

Hörkner W and Müller-Buschbaum H (1976) Zur kristallstruktur von $\mathrm{CaAl}_{2} \mathrm{O}_{4}$. Journal of Inorganic and Nuclear Chemistry 38(5): 983-984 (in German).

Idrissi M, Diouri A, Damidot D et al. (2010) Characterisation of iron inclusion during the formation of calcium sulfoaluminate phase. Cement and Concrete Research 40(8): 1314-1319.

Irran E, Tillmanns E and Hentschel G (1997) Ternesite, $\mathrm{Ca}_{5}\left(\mathrm{SiO}_{4}\right)_{2} \mathrm{SO}_{4}$, a new mineral from the Ettringer Bellerberg/Eifel, Germany. Mineralogy and Petrology 60(1-2): 121-132.

Jen G, Skalamprinos S, Whittaker M et al. (2017) The impact of intrinsic anhydrite in an experimental calcium sulfoaluminate cement from a novel, carbon-minimized production process. Materials and Structures 50(2): 1-11.

Juenger MCG, Winnefeld F, Provis JL and Ideker JH (2011) Advances in alternative cementitious binders. Cement and Concrete Research 41(12): 1232-1243. 
Kirfel A and Will G (1980) Charge density in anhydrite, $\mathrm{CaSO}_{4}$, from X-ray and neutron diffraction measurements. Acta Crystallographica. 36(12): 2881-2890.

Larson AC and Von Dreele RB (2004) General Structure Analysis System (GSAS). Los Alamos National Laboratory, Los Alamos, NM, USA, Report LA-UR.

Louisnathan SJ (1971) Refinement of the crystal structure of a natural gehlenite, $\mathrm{Ca}_{2} \mathrm{Al}(\mathrm{Al}, \mathrm{Si})_{2} \mathrm{O}_{7}$. Canadian Mineralogist 10(5): 822-837. Mumme WG, Hill RJ, Bushnell-Wye G and Segnit ER (1995)

Rietveld crystal structure refinements, crystal chemistry and calculated powder diffraction data for the polymorphs of dicalcium silicate and related phases. Neues Jahrbuch fuer Mineralogie - Abhandlungen 169(1): 35.

Pliego-Cuervo YB and Glasser FP (1978) Role of sulphates in cement clinkering: the calcium silicosulphate phase. Cement and Concrete Research 8(4): 455-459.
Roine A (2002) HSC Chemistry. Outokumpu Research Oy, Pori, Finland.

Sasaki S, Prewitt CT, Bass JD and Schulze WA (1987)

Orthorhombic perovskite $\mathrm{CaTiO}_{3}$ and $\mathrm{CdTiO}$ :

Structure and space group. Acta Crystallographica

Section C 43: 1668-1674, https://doi.org/10.1107/ S0108270187090620.

Thompson P, Cox DE and Hastings JB (1987) Rietveld refinement of Debye-Scherrer synchrotron $\mathrm{X}$-ray data from $\mathrm{Al}_{2} \mathrm{O}_{3}$. Journal of Applied Crystallography 20: 79-83, https://doi.org/10.1107/ S0021889887087090.

Touzo B, Scrivener KL and Glasser FP (2013) Phase compositions and equilibria in the $\mathrm{CaO}-\mathrm{Al}_{2} \mathrm{O}_{3}-\mathrm{Fe}_{2} \mathrm{O}_{3}-\mathrm{SO}_{3}$ system, for assemblages containing ye'elimite and ferrite $\mathrm{Ca}_{2}(\mathrm{Al}, \mathrm{Fe}) \mathrm{O}_{5}$. Cement and Concrete Research 54: 77-86, https://doi.org/10.1016/j.cemconres. 2013.08.005.

\section{How can you contribute?}

To discuss this paper, please submit up to 500 words to the editor at journals@ice.org.uk. Your contribution will be forwarded to the author(s) for a reply and, if considered appropriate by the editorial board, it will be published as a discussion in a future issue of the journal. 